\title{
A Numerical Approach to the Customer Lifetime Value
}

\author{
Darkhijav Bayanjargal1, Batsukh Davaasuren², Rentsen Enkhbat ${ }^{2}$ \\ ${ }^{1}$ School of Applied Science and Engineering, National University of Mongolia, Ulaanbaatar, Mongolia \\ ${ }^{2}$ Business School, National University of Mongolia, Ulaanbaatar, Mongolia \\ Email: bayanjargal@seas.num.edu.mn,davaasuren10@yahoo.com, enkhbat46@gmail.com
}

How to cite this paper: Bayanjargal, D., Davaasuren, B. and Enkhbat, R. (2018) A Numerical Approach to the Customer Lifetime Value. iBusiness, 10, 85-91. https://doi.org/10.4236/ib.2018.102005

Received: February 11, 2018

Accepted: June 4, 2018

Published: June 7, 2018

Copyright $\odot 2018$ by authors and Scientific Research Publishing Inc. This work is licensed under the Creative Commons Attribution International License (CC BY 4.0).

http://creativecommons.org/licenses/by/4.0/

\begin{abstract}
In this paper, we show that it is possible to estimate discount rate or cost of capital in the calculation of customer lifetime value $(C L V)$ for a company using numerical methods instead of the traditional financial approaches. We propose an estimation formula for retention period that the company should keep the customers in order to gain certain benefit from them. We also apply our theoretical approaches to the Mongolian mobile service at company level using statistical data from 2005 to 2016. Some numerical results are included.
\end{abstract}

\section{Keywords}

Customer Lifetime Value, Discount Rate, Retention Period, Newton's Method

\section{Introduction}

Customers are one of the main assets of a company that should be assessed and regulated. Customer lifetime value $(C L V)$ is gaining increasing importance as a marketing metric in both academia and practice [1]. The literature has generally defined $C L V$ in many ways that differ subtly. For example, Dwyer (1997) defined $C L V$ as the present value of the expected benefits (e.g., gross margin) less the burdens (e.g., direct costs of servicing and communicating) from customers. Kumar, Ramani and Bohling [2] defined $C L V$ as the sum of cumulated cash flows discounted using the weighted average cost of capital of a customer over his or her entire lifetime with the firm [3]. Estimating the Customer lifetime value gives an opportunity to predict future investments and benefits of a company from its customers.

Customer lifetime value models mainly focus on the estimation of customer 
lifetime value and customer relationship management. However, it is very important to consider ways of finding the discount rate and retention period which are main components of the models. So we address these two issues in our paper. From a mathematical perspective, the discount rate is a solution of nonlinear equation and the retention period can be calculated from the general model. From a managerial perspective, the discount rate and retention period are important components of the models and decision making process. It is possible to find the discount rate using numerical methods.

The paper is organized as follows. In Section 2, we consider a general $C L V$ model and Newton's method for estimating the discount rate and generate a formula for retention period. In Section 3, we briefly introduce about Mongolian mobile service and show the numerical results. And we summarize our findings.

\section{Research Methodology}

\subsection{Model}

Customer lifetime value $(C L V)$ is generally defined as the present value of all future profits obtained form a customer over his or her life of relationship with a firm . $C L V$ is similar to the discounted cash flow approach used in finance [1].

$$
C L V=\sum_{t=0}^{n} \frac{\left(p_{t}-c_{t}\right) r_{t}}{(1+i)^{t}}-A C
$$

where $p_{t}$ is the price paid by a customer and $c_{t}$ is the direct cost of servicing the customer at time $t, i$ is the discount rate or cost of capital for the firm, $r_{t}$ is the probability or customer repeat buying at time $t, A C$ is the acquisition cost, and $n$ is the time horizon for estimating $C L V$.

For simplicity, if we assume that a customer generates margin $m_{t}$ for each period $t$, the retention rate is $100 \%$ and discount rate or cost of capital for a firm is $i$, then the customer lifetime value is calculated by the following formula:

$$
C L V=\sum_{t=0}^{n} \frac{m_{t}}{(1+i)^{t}}
$$

where $n$ is time horizon for estimating $C L V$. A key decision is what time horizon to use for estimating $C L V$. Typically, three to five year is reasonable. With this information and estimated other variables, we can calculate $C L V$ using spreadsheet analysis.

\subsection{Numerical Methods for the Estimation of Discount Rate}

Discount rate or the cost of capital is used to find the present profits from a customer. In most cases, discount rate is considered as a constant about $8-16$ percent in customer lifetime value calculations [4].

In our work we use a numerical method which is called the Newton's method to estimate the discount rate when margins and customer lifetime value are known. Newton's method is one of the most powerful and well-known numeri- 
cal methods for solving a root-finding problem [5]. Let introduce the function

$$
\varphi_{t}(i)=\frac{m_{t}}{(1+i)^{t}}
$$

Then we can compute $i$ from the following equation

$$
C L V=\sum_{t=0}^{n} \varphi_{t}(i)
$$

for given $C L V$ and $m_{t}$. Equation (4) has a unique solution [6]. In order to use the method, we can reformulate the equation as follows:

$$
F(i)=\sum_{t=0}^{n} \varphi_{t}(i)-C L V=0
$$

So the unique solution can be estimated by the following stage of Newton's iteration method which starts with an initial approximation $\dot{i}_{0}[6]$ :

$$
i_{k}=i_{k-1}-\frac{F\left(i_{k-1}\right)}{F^{\prime}\left(i_{k-1}\right)}, k=1,2,3, \cdots
$$

\subsection{Retention Period}

Retention period is a time period that a customer stays with the company with certainly. For simplicity, if we assume that the average margin each customer per year is constant, that is $\left.m_{t}=m,(t=0,1,2, \cdots, n)\right)$, then the formula (1) has the form

$$
C L V=m\left(1+\frac{1}{i}\left[1-\frac{1}{(1+i)^{n}}\right]\right)
$$

So we can find $n$, retention period, from the equation as:

$$
n=\frac{\ln \left(1-\left[\frac{C L V}{m}-1\right] i\right)}{\ln \left(\frac{1}{1+i}\right)}
$$

for given $m$ and $C L V$.

\section{Numerical Results}

\subsection{Brief Introduction of Mongolian Cellular Service}

It has been more than 20 years since Mobicom corporation first introduced mobile service in Mongolia based on GSM in 1996. As a result of market competition, today there are four major mobile operators such as Mobicom corporation, Unitel, Gmobile and Skytel companies.

In our work, we used the statistical data such as number of subscribers, total income and investment of mobile service from 2005 to 2016 obtained by the annual reports of Communications Regulatory Commission of Mongolia to estimate the main indicators of mobile service operators. According to the annual reports, the number of subscribers is increasing year by years. From the Figure 1, we can see that 3409.4 thousand subscribers are actively using mo- 
bile phones in their everyday life in 2016, which is about 6 times compared to those of 2005.

As cellular telephone companies updated equipment and technology from year to year, the number of subscribers and types of service have increased and tariffs have decreased to some extent to compete with the ever-increasing market. Cellular is presently focused on prepaid and postpaid 2 types of product on the market telecommunication markets. Most of subscribers, 87.72 percent, are prepaid users.

Figure 2 shows the market share of mobile operators. In 2005, Mobicom was the largest market for cellular telecommunications and dropped to 42 percent in 2016. The second largest cellular telephone company is Skytel, accounting for 32 percent of the market in 2016. Statistics show that the company's share in the market for the last three years is almost constant. This shows that the companies are operating consistently and on the other hand, most users are loyal to the operator.

We showed the total revenue of Mobile service and total found raising to the state budget from Mobile service in the Figure 3. According to the last 6 years, the total income of the sector has increased until 2014 where it reached 454.7 billion MNT, but revenue has fallen in the last two years. The cellular service sector annually accounts for 17.7 percent of its total revenue to the state budget and 21 percent for investment. Since technology is constantly being updated, investments in this sector are more important than other sectors.

In our work, we assume that the total profit generated by mobile operators is 20 percent of its total income, since we are lack of information about the total cost of mobile companies. So we can find the average margin per customer for a mobile service company by dividing the total profit to the number of active subscribers. Figure 4 shows the time trend for the average margin of a mobile service operator. According to the estimation, in 2011, the average margin per customer was about 39.3 thousand MNT and there was an increase in the average margin from 2012 to 2014 where it reached 35.1 thousand MNT. In recent

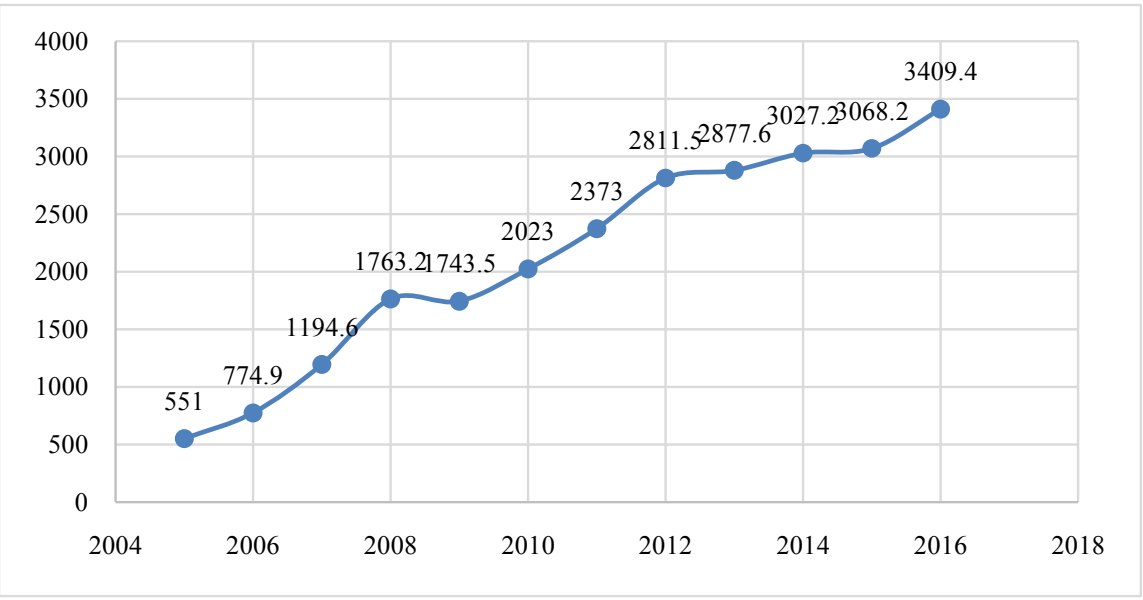

Figure 1. Number of active subscribers/thous. person/. Source: http://www.crc.gov.mn/. 


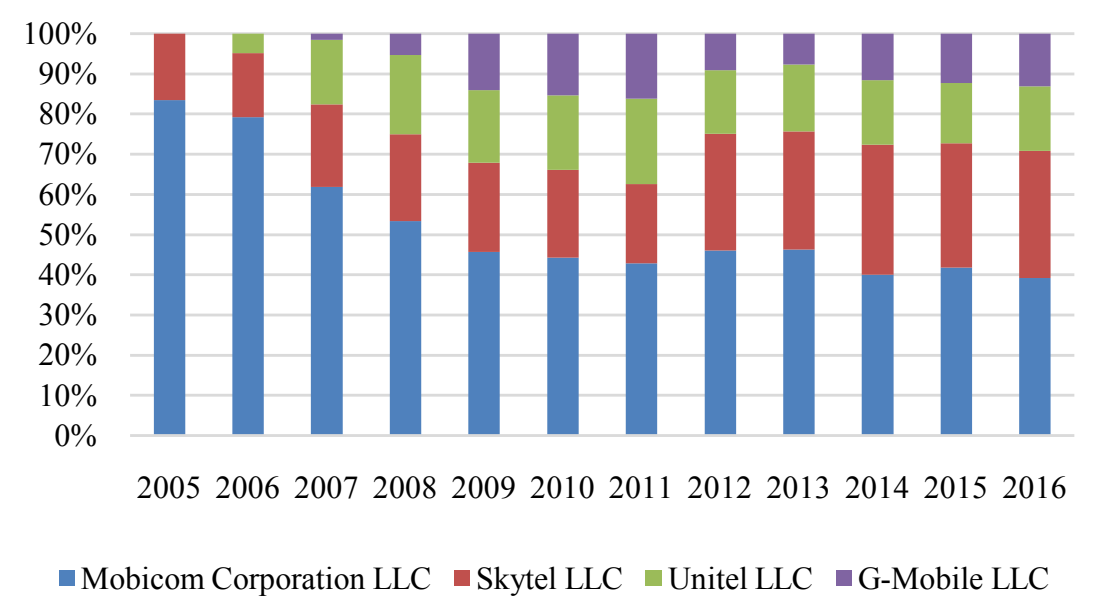

Figure 2. Market share of mobile companies. Source: http://www.crc.gov.mn/.

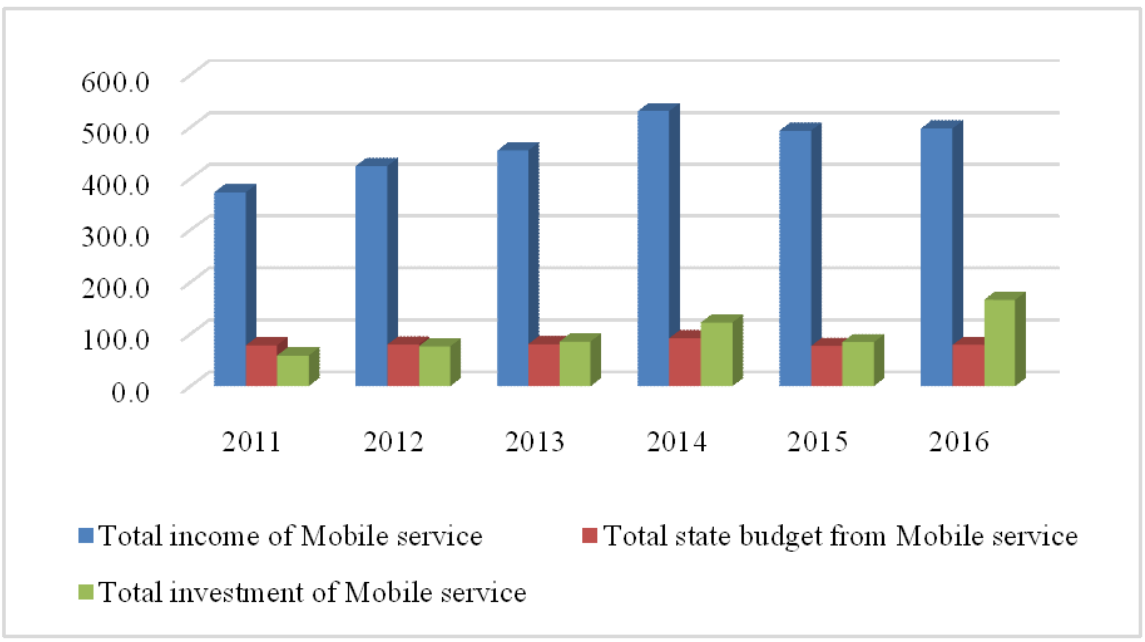

Figure 3. Total income and state budget of Mobile service /bill. MNT/.

years, this amount has dropped to 29.2 thousand MNT in 2016.

\subsection{Estimation of Discount Rate and Retention Period}

To find discount rate numerically, we solved the following problem by Newton's method starting with the initial approximation $i_{0}=0.001$ using $\mathrm{C}++$ program:

$$
C L V=\sum_{T=0}^{5} \frac{m_{t}}{(1+i)^{t}}
$$

where $m_{t}$ and $C L V$ are given. Results are shown in Table 1.

According to the calculation, if the customer life time value is 130 thousand MNT, discount rate should be 18 percent, however if it is 170 thousand MNT then discount rate must be smaller, that is 4.6 percent. We also showed the iteration numbers which are required to achieve within 0.0001 accuracy.

Since there was tendency to stabilize the average margin per customer of a mobile service company of Mongolia, we assumed that the average margin for 
40.0

35.0

30.0

25.0

20.0

15.0

2011

2012

2013

2014

2015

2016

Figure 4. Annual average margin per customer/thous. MNT/. Source: http://www.crc.gov.mn/

Table 1. Discount rate and number of iterations.

\begin{tabular}{cccc}
\hline & Customer lifetime value, /thous. MNT/ & Discount rate, \% & Iteration number \\
\hline 1 & 110 & 29 & 8 \\
2 & 130 & 18 & 6 \\
3 & 150 & 11 & 5 \\
4 & 170 & 4.6 & 4 \\
\hline
\end{tabular}

each customer is constant, that, about 32 thousand MNT and calculated how long the company should retain the customers using the Equation (9) to gain certain profit from the customers. Numerical results are given by the following table.

From Table 2, we can see that if discount rate is 8 percent, it takes about 7 years to gain 200 thousand MNT from a customer whose average margin is about 32 thousand MNT per year where as it takes 9 years when discount rate is assumed 12 percent. Using the calculation, the company can make prediction about its profit after several years.

\section{Conclusions}

1) We showed that it is possible to find the discount rate using the numerical methods. We used the Newton's method to solve the problem.

2) We proposed a formula for calculating retention period of $C L V$ model for a constant margin and any customer lifetime values.

3) We applied the proposed approach to the Mongolian mobile service at company level and estimated the average margin per customer and $C L V$ of a mobile service company using annual data by the Communications Regulatory Commission of Mongolia. 
Table 2. Calculation of retention period.

\begin{tabular}{lccc}
\hline & Discount rate, $\%$ & Retention period \\
\hline 1 & 8 & 200 & 7 \\
2 & 8 & 150 & 5 \\
3 & 12 & 200 & 9 \\
4 & 12 & 150 & 5 \\
5 & 16 & 200 & 11 \\
6 & 16 & 150 & 6 \\
\hline
\end{tabular}

4) We hope that our approach will provide the tools for estimating some of main components of $C L V$ model but also give a theoretical contribution in the field.

\section{References}

[1] Gupta, S., Hanssens, D., et al. (2006) Modeling Customer Lifetime Value. Journal of Service Research, 9, 139-155. https://doi.org/10.1177/1094670506293810

[2] Gupta, S., Lehmann, D.R. and Stuart, J.A. (2004) Valuing Customers. Journal of Marketing Research, 41, 7-18. https://doi.org/10.1509/jmkr.41.1.7.25084

[3] Singh, S.S. and Jain, D.C. (2013) Measuring Customer Lifetime Value: Models and Analysis. Faculty and Research Working Paper, INSEAD, The Business School of the World.

[4] Gupta, S. and Lehmann, D.R. (2003) Customers as Assets. Journal of Interactive Marketing, 17.

[5] Burden, R.L. and Faires, J.D. (2011) Numeraical Analysis. 9th Edition.

[6] Serod, B. and Enkhbat, R. (2010) Optimization Approach to the Valuation Model. IJPAM, 60, 57-62. 